\title{
Pre-Class Tutorial (PCT) to Improve Understanding of Prospective Physics Teacher Concepts in Basic Physics Course
}

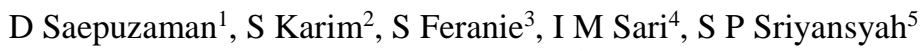 \\ \{dsaepuzaman@upi.edu $\left.{ }^{1}\right\}$ \\ Department of Physics Education, Universitas Pendidikan Indonesia, Bandung, Indonesia \\ Department, School of Postgraduate Studies, Universitas Pendidikan Indonesia, Bandung, Indonesia
}

\begin{abstract}
This research aim to the understanding of the basic physics concepts of preservice physics teacher that shows the conceptual difficulties of Basic Physics concept. This finding is the fact in determining alternative solution to support the achievement of more optimal learning outcomes, one of which is the development of Pre-Class Tutorial (PCT). The method used is a quasi-experimental method. A total of three grade student who took the Basic Physics I course in the Physics Education Study Program were involved to collect research data. The research instrument used in the form of PCT to get a description of students' thought processes on the concepts of Physics and the comprehension test of the concept of system of particle and Momentum to determine the understanding of Basic Physics concepts. The results showed that the using of PCT helped students construct concepts of physics and improve understanding of prospective physics teacher concepts.
\end{abstract}

Keywords: Prospective Teacher, Physics Education, Learning Outcomes

\section{Introduction}

In higher education learning context, a course is held in order to achieve the Learning Outcomes (LO) that specifically written in course learning outcomes. As a part of achieving these learning outcomes, Introductory of Physics course has an important role to develop students' understanding of fundamental physics concepts. Therefore, teachers of Introductory of Physics have to create the best plan to create the learning that facilitates students to construct scientific understanding in order to achieve that determined learning outcomes. Nevertheless, based on the fact in the practice, most of students did not success achieving the learning outcomes. This fact comes from the result of physics test in formative test that more than $50 \%$ students did not reach the standard score. This finding relevant to Mc Dermott finding in which even after finish the course, students still experience the difficulties of basic concept [1]. Even though, students tried to solved many problems written in text book along the course, the fact showed that there are still many students held conceptual difficulties [2]. That condition might be come from the students who unable to get focus on the skills that they have to be built to solve the problems in flexible and reliable in many contexts (such as interpretation and or construction the physics representation from the problem). They only desire how to answer the questions as fast as possible [3]. 
The conceptual difficulties faced by students from all around the world have been documented in many physics education researchs [4], [5]. Most of the reports investigated the students' conceptual difficulties in Introductory of Physics due to the strategic and vital of that course in constructing students' understanding in fundamental physics concepts as a basic for students in comprehending advance concepts such as mechanics and thermodynamic. This phenomenon is not only happened in abroad, but also in Indonesia. Pre-service Physics Teachers in Indonesia are also experience the conceptual difficulties [6][7][8].

Learning process is one of the components that play an important role in lacking of students' conceptual understanding. Although there are many results of physics education researchs related to learning strategy that succed to improve students' understanding [9][10], still the implementation in different population showed the un-optimal achievement due to the diverse of students characteristic (reasoning ability, learning styles, pre-knowledge, and mathematics ability) [11] [12]. Based on the experience of authors, the whole learning process tend to started from sharing the information directly through lecturing or power point and ended by solving the sample problems and exercise the home work. This learning process is lack of facilitating students to construct their knowledge by themselves [13]. Students tend to receives the physics concept without further explanation, even though some times teacher give the chance for students to ask the question, but students who ask the question are still rare.

Students rarely read lecture material before coming to college, even though it has been reminded by lecturers many times. This situation is in line with previous research reports. Although the report of Heiner et al. [14] mentions $80 \%$ of students from the University of British Columbia campus complete the initial reading assignments given before lectures, but the majority of research reports indicate that only less than $40 \%$ of students on campus, such as the University of Colorado, Boulder, Millersville University, and Rensselaer Polytechnic Institute, who reads books before coming to class [15] [16]. Whereas if students prepare themselves well before lecturing, such as by reading lecture material first, lectures will effectively build understanding of concepts and practice students' problem solving abilities [17].

Previous research, mentions some of the difficulties associated with students in the concept of momentum as follows. First, students have difficulty in applying the concept of momentum in various physical situations, especially new physical situations or physical situations that are stated in descriptive form. Students still often solve the problem of momentum which is stated descriptively, not in the form of numbers, without using the Physics principles that have been learned. Second, students view the concept of momentum as the concept of energy, which is a scalar quantity. Third, students have difficulty in applying the law of conservation of momentum in new physical situations, especially in the context of problems that have a changing mass. Fourth, there are errors of thinking related to the validity of the law of momentum for objects, not just for systems. Fifth, students have difficulty in describing momentum, changes in momentum, impulses expressed in vector representations [18].

The concept of momentum is an important concept in physics as well as the concept of energy [9] [10]. Close and Heron [19] report that students tend to view the law of momentum as a law of scalar quantities, not as vectors. Graham and Berry's research [20] of more than 500 students in England (ages 17-18) also concluded that most students understood momentum as a scalar quantity. In addition to understanding momentum as a scalar quantity, students also have difficulty connecting the mathematical equation of momentum in the collision case with the phenomenon of motion they observe. The fact that students have difficulty with the concept of momentum, contrasts with observations during learning. During the lecture process, direct observations show that students are quite familiar with the concept of the delivered momentum. Most students seemed to be able to attend lectures and accept the material being studied. 
Realizing this situation, there needs to be an effort to redesign learning that specifically can help students prepare well before lectures and at the same time support learning that facilitates students to construct their own understanding. Because after all the good learning prepared by a lecturer, but if students are passive in answering qualitative / inquiry questions to construct concepts due to not preparing themselves before lectures, then learning will only lead to mere information provision. While this kind of learning has proven ineffective in increasing students' conceptual understanding [13]. Previously reported efforts to stimulate students to prepare well before lectures are through the use of multimedia modules [21], the initial assignment of reading certain parts of a book accompanied by online quizzes [14], and the provision of some questions selected from books later via email before lectures [22].

Curriculum development in Physics learning which rests on the investigation of students' conceptual understanding will continue. Not only in lectures in Basic Physics anymore, but developed in lectures in advanced physics, such as Modern Physics [23] and Quantum Mechanics [24]. This certainly makes the development of learning methods and strategies must follow the findings of students' conceptual difficulties on the specific concepts in the lecture.

So far, the Physics education research community has succeeded in developing various methods and learning strategies that support conceptual understanding and problem solving abilities. Van Heuvelen [10] designed the Overview Case Study Physics (OCS) learning supported by Concept First by Gautreau [25]. This learning emphasizes active, cooperative learning and utilizes diverse representations to solve problems. Heller et al. [10] also devised a problem-solving strategy through collaborative learning. Eric Mazur designed a Peer Instruction (PI) study to teach Physics at Harvard University [26]. While McDermott [27] conducted intensive and ongoing research at the University of Washington (UW) to develop the Physics by Inquiry curriculum and Tutorial in Introductory Physics. The effectiveness of all these methods has been documented by many research reports, including the tutorial method developed by McDermott [28].

The tutorial method allows students to examine for themselves the inconsistencies in understanding concepts and reasoning errors in their answers [29]. However, its use in a student population that is not familiar with qualitative conceptual questions requires more intensive efforts. Nevertheless, tutorials have been shown to be effective in increasing the ability of students to solve qualitative and quantitative questions [29]. Tutorials have also been widely adopted in various lectures and laboratory activities, such as mathematics [30], quantum mechanics, astronomy, and Basic Physics practicums [31]. The overall results of the research are the rationales for the development of PCTini. The tutorial developed by McDermott at UW is a supplement used after learning to replace a recitation session. Meanwhile, by looking at the effectiveness of the use of tutorials on pre-practicum activities [31] the impact of giving assignments in the form of conceptual questions that support improved learning outcomes [32] and to overcome the weaknesses of students in reading books before lecturing, then on the basis of the rational PCT was designed. PCT in the design uses several considerations, in addition to the development in constructivism questions, PCT is also designed by considering real or contextual phenomena. This is because One of ways to begin the improvement in physics learning is investigating the students' thought of some concept or phenomenon [33] [34]. 


\section{Methods}

The method used is a quasi-experimental method that aims to determine the effectiveness of the use of PCT in improving understanding of the concept of Prospective Physics Teachers in Basic Physics lectures. Subjects involved in this research were 82 students in semester III Physics education study program in 2015/2016 academic year, 82\% academic year 2016/2017, and 82/2018 academic year 82 students. For students in the academic year 2015/2016 and 2016/2017 they still apply Basic Physics I learning lessons without using PCT, while the academic year 2017/2018 already uses PCT. The research instrument used in the form of PCT to get a description of students' thought processes on the concepts of physics and concept mastery tests through midterm and final exam. For UTS includes measurement and vector system material, motion in one dimension, motion in two dimensions, dynamics, effort and energy, linear momentum and collision, while UAS material is rotation, balance, gravity, fluid mechanics, vibrations, waves, and thermodynamic introduction. Improved understanding of pre service physics teacher concept is identified by comparing the average achievement of student scores on Conceptual understanding test for the academic year 2015/2016, 2016/2017 and $2017 / 2018$

\section{Results and Discussion}

\subsection{PCT : One example in Parabolic Motion}

This tutorial is structured with the aim of training students to balance quantitative reasoning and problem solving with qualitative reasoning and conceptual understanding. In addition, train students to routinely read Physics books word by word carefully before lecturing and not just to make books as a reference that is used when there is homework and assignments. If students have prepared themselves well before lecturing, they can automatically support an active learning in the classroom. The description of the characteristics and design of the PCT used at UPI is explained by taking the example of parabolic motion material as follows.

\subsection{Characteristic Descriptive}

The following are some of the basic considerations in the development process then will be the characteristic of PCT.

(a) The questions in the tutorial are arranged conceptually and systematically by considering the level of thought and sequence of concepts of Physics, according to the constructivist principle [35].

(b) The tutorial was developed into two parts. The first part contains questions for constructing Physics concepts, while the second part contains questions for applying Physics concepts that refer to the number of questions selected in the reference book used.

(c) In the concept implementation section, the problems presented are made in the order of Physics concepts and are tiered from level I to level III, both quantitative and qualitative. Level I contains questions that only require one step to complete and are relatively easy. Level II contains questions that require a deeper understanding. This means that it is possible not only to require one step of completion and possibly to link with other concepts as needed. Level III questions are the most challenging for students. In the question of stage III, the demand for 
resolution not only links between conceptual relations, but also allows students to use higher mathematics, for example related to the problem of maximum critical points. This solution requires not only physical concepts, but also mathematical concepts such as derivative, integral, and series concepts. In general, the order of these levels expresses higher demands of thinking both in terms of the level of thinking and the complexity of the given Physics content.

\subsection{Design of PCT}

The PCT was developed through an ongoing intensive research. The stages of development in outline consist of two stages, namely the stage of diagnosing problems and the stage of developing tutorials. At the stage of diagnosing the problem is done by identifying the difficulty of students on certain concepts. The method used is similar to that used by the Physics Education Research Group (PER) pioneered by L.C. McDermott, to investigate the understanding of concepts and conceptual difficulties experienced by students [4]. Two methods are used by PER, namely individual demonstration interviews and descriptive studies through written tests [4]. Observations and interactions with students in the classroom also provide in-depth information about how students learn well. The development phase of the tutorial is by structuring systematic conceptual questions in accordance with research findings, levels of thinking and the sequence of constructs of Physics concepts. Then the compiled tutorial is tested on a sample of students who take the Basic Physics lecture. Unit test results provided after learning become an evaluation material to revise weaknesses contained in the PCT that has been prepared. PCT samples for velocity and acceleration vector material on parabolic motion are presented in Figure 1.

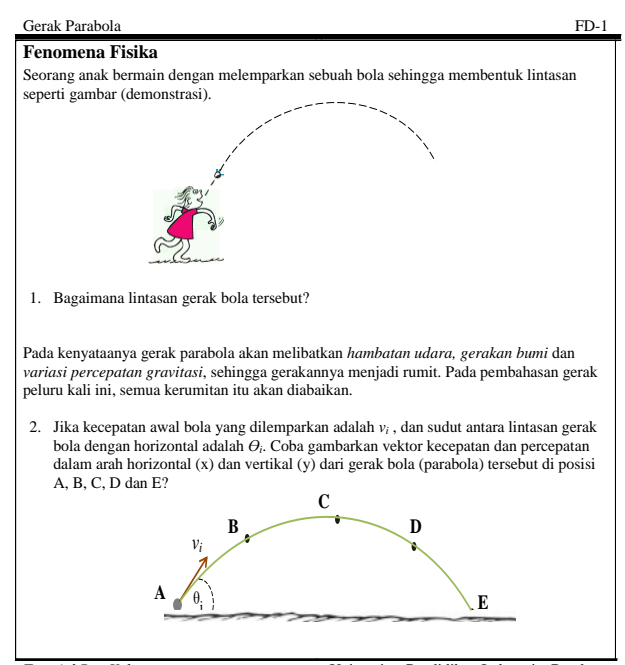

Fig. 1. PCT sample to to construct the concept of velocity vectors and acceleration in parabolic motion.

The questions in the PCT parabolic motion are based on systematic material and previous findings related to student difficulties in two-dimensional motion. In the concept of parabolic motion it was found that students experienced the following difficulties. First, describe the component vectors in the $\mathrm{x}$ (horizontal) and $\mathrm{y}$ (vertical) directions. Second, distinguish the velocity vectors, velocity component vectors, velocity vector components in the $\mathrm{x}$ and $\mathrm{y}$ directions. Third, it focuses on memorizing the time formula taken by bullets for the half- 
parabolic trajectory, maximum height, and maximum farthest distance. Fourth, always assume the final velocity of the object that moves the parabolic motion when it touches the ground is always zero. Fifth, the velocity of the zero object at the top (even though the velocity is in the zero vertical direction). Sixth, acceleration is owned by objects in both $\mathrm{x}$ and $\mathrm{y}$ directions. Seventh, it was found that some students used the cosine sine rules of triangles in determining distance / height and vice versa (whereas determining the distance / height based on speed information) [18]. Departing from these findings, PCT was designed. Detailed explanation of each PCT part of the parabolic motion material is described as follows at Figure 2.

Question number \# 1 is structured to overcome the student's conception which is often when asked about parabolic motion always answering parabolic motion is a combination of GLB and GLBB, even though the definition of parabolic motion is viewed in terms of the trajectory of the motion of objects. Therefore, item \# 1 aims to emphasize that the definition of parabolic motion in terms of the trajectory of the motion of objects, namely the motion of objects whose parabolic trajectories. After using PCT, students are expected to realize that in addition to the definition of parabolic motion in terms of the trajectory of the motion of objects, also quantitative analysis related to physical quantities in parabolic motion can be viewed from the understanding that parabolic motion is a combination of GLB in the horizontal direction ( $\mathrm{x}$-axis) and GLBB direction vertical direction (y-axis).

Next question number \# 2 asks students to describe the velocity and acceleration vector components in the $\mathrm{x}$-axis (horizontal) and $\mathrm{y}$-axis (vertical) directions whose values change over time. Shaffer \& McDermott reported that students had difficulty in determining the acceleration vector in object motion vertically or horizontally [15]. The authors' findings also show that most students describe the velocity vector decreasing in magnitude to the highest point and then increasing again until it reaches the ground, both on the $\mathrm{x}$-axis and the $\mathrm{y}$-axis. Whereas the speed only changes in the vertical direction of the $y$-axis, whereas in the horizontal direction the $\mathrm{x}$ axis is constant.

The question number \# 3 is arranged to overcome the students' difficulty finding, among others: (1) the magnitude and direction of the speed change both in the x-axis and $y$-axis directions. In fact, in parabolic motion the speed changes only in the vertical direction of the $y$ axis (GLBB) while in the horizontal direction the $\mathrm{x}$-axis is constant (GLB); (2) the acceleration changes in both the $\mathrm{x}$-axis and $\mathrm{y}$-axis directions. Acceleration is negative because it is slowed down, so that both the speed in the $\mathrm{x}$-axis and the $\mathrm{y}$-axis are decreasing in magnitude due to slowing down. In fact, the acceleration of an object in a constant parabolic motion both large and direction that is only in the y-axis direction, equal to the acceleration of gravity; (3) the biggest acceleration of the ball is at the initial point when starting to be thrown while the smallest is at the highest point, because the ball is still for a moment. In fact, the acceleration of an object in a constant parabolic motion both large and direction that is only in the y-axis direction, equal to the acceleration of gravity. The momentary silence at the highest point means the instantaneous velocity in the vertical direction of the $y$-axis (only in the $y$-axis) is equal to zero. 


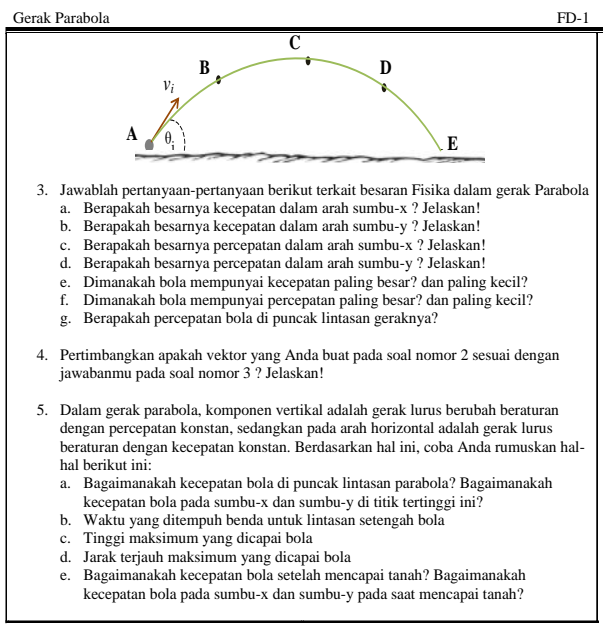

Fig. 2. PCT examples for constructing each concept and equation physical quantities in parabolic motion.

Errors of reasoning and inconsistencies in student answers contained in number \# 2 and \# 3 were subsequently identified using item number \# 4 . This item aims to identify the consistency of student understanding regarding the physics magnitude of speed and acceleration in the $\mathrm{x}$ axis and $y$-axis directions as described in the previous answer. In addition, at the same time reinforce student understanding of the velocity vector and the object acceleration vector in the $\mathrm{x}$-axis and $\mathrm{y}$-axis direction and their use for general and special conditions. Findings of the results of the implementation of this tutorial in learning show inconsistencies in students' answers regarding the amount of physics they answer verbally qualitatively and vector / pictorially.

The question number \# 5 directs students to construct the concept of physical quantities in a parabolic motion under special conditions, such as the highest point and the maximum farthest distance. Previous research findings [18] showed that some students had a conception of the velocity of the object at the top equal to zero, both in the horizontal (x-axis) and vertical (y-axis) directions. Whereas the speed at the top is equal to zero only in the $y$-axis component, whereas in the $\mathrm{x}$-axis direction the speed is constant (GLB).

In general, the results of understanding the concept of prospective teachers after PCT implementation in learning obtained by understanding scores at the midterm exam (ME) and final exam (FE) for each academic year are presented in Table 1.

Table 1. Recapitulation of the understanding scores of Basic Physics concepts for each academic year.

\begin{tabular}{lcccccc}
\hline Academic Year & \multicolumn{2}{c}{$2015 / 2016$} & \multicolumn{2}{c}{$2016 / 2017$} & \multicolumn{2}{c}{$2017 / 2018$} \\
\hline Test & ME & FE & ME & FE & ME & FE \\
Average Score & 60.94 & 63.71 & 61.07 & 63.7 & 75.87 & 74.04 \\
\hline
\end{tabular}

Based on this data, if viewed from the overall score acquisition by reviewing the average overall score (midterm and final exam) the difference in the acquisition of concept understanding scores for each academic year is presented in Figure 3. 


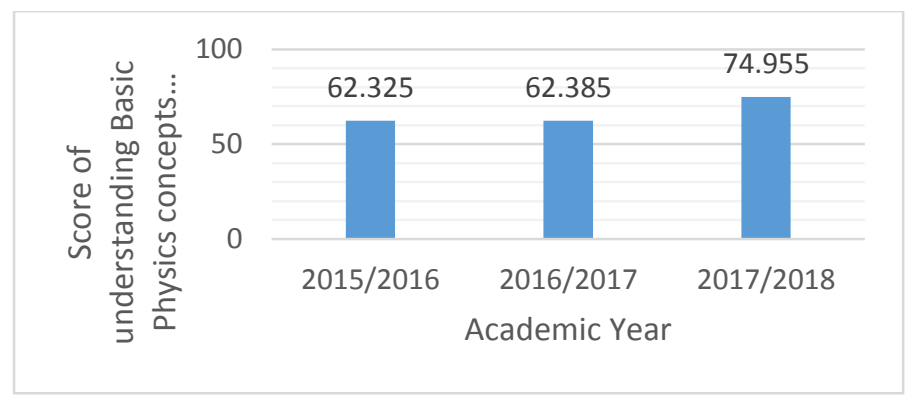

Fig. 3. Score of understanding of Basic Physics concepts for each academic year.

Figure 3 shows that there is an increase in the average achievement score of the understanding of the material system of particle systems and momentum. Further analysis to see whether the differences are significant or not is done by further testing (Post Hoc Analysis). In general, the results of further tests are presented in Figure 4.

Multiple Comparisons

\begin{tabular}{|c|c|c|c|c|c|c|}
\hline \multirow[b]{2}{*}{ (D) VAR00001 } & \multirow[b]{2}{*}{ (J) VAR00001 } & \multirow[b]{2}{*}{$\begin{array}{c}\text { Mean } \\
\text { Difference (I- } \\
\mathrm{J})\end{array}$} & \multirow[b]{2}{*}{ Std. Error } & \multirow[b]{2}{*}{ Siq. } & \multicolumn{2}{|c|}{$95 \%$ Confidence Interval } \\
\hline & & & & & Lower Bound & Upper Bound \\
\hline \multirow[t]{2}{*}{1.00} & 2.00 & -.06098 & .73014 & .996 & -1.7882 & 1.6662 \\
\hline & 3.00 & $-12.62805^{x}$ & .62782 & .000 & -14.1139 & -11.1422 \\
\hline \multirow[t]{2}{*}{2.00} & 1.00 & .06098 & .73014 & .996 & -1.6662 & 1.7882 \\
\hline & 3.00 & $-12.56707^{\pi}$ & .66389 & .000 & -14.1389 & -10.9952 \\
\hline \multirow[t]{2}{*}{3.00} & 1.00 & $12.62805^{x}$ & .62782 & .000 & 11.1422 & 14.1139 \\
\hline & 2.00 & $12.56707^{\pi}$ & .66389 & .000 & 10.9952 & 14.1389 \\
\hline
\end{tabular}

${ }^{*}$. The mean difference is significant at the 0.05 level.

Fig. 4. The results of the follow-up test (Post Hoc Analysis) are related the significance of the difference in scores for each generation.

Based on the data in Figure 4, it appears that the scores of students' conceptual understanding of the 2017/2018 academic year (Var 000001-3.00) differ significantly both with the 2016/2017 academic concept understanding score (Var 000001-200) and 2015/2016 (Var 000001- 1.00$)$. This is indicated by the value of sig. 0,000 ( $\mathrm{Sig}=0,000<0.050)$. Based on this data in Figure 4, the results shows that there is an increased understanding of the concept after the use of PCT.

This increase in performance is certainly inseparable from the role of PCT used. This is based on a change in student thinking (as outlined in the tutorial) found during the learning process. Most students after going through group discussions and class discussions experienced an increase in concept understanding. Giving PCT which is presented in the form of conceptual questions directed by using various representations makes students think more and consider in detail their answers. In addition, classroom learning becomes more active and richer with interactive conceptual discussions between students or between students and lecturers. Lectures are no longer monotonous and informative, but rather become a place of discussion to solve problems found by students before entering class. 


\section{Conclusion}

The use of PCT in lectures in Basic Physics has succeeded in increasing the achievement of student learning outcomes as indicated by an increased score understanding of the concept of particle systems and momentum. This study also provides alternative learning to change conventional learning that tends to be informative into an active and cooperative quality conceptual learning. PCT which emphasizes aspects of conceptual understanding is very useful to stimulate students to read reference books in Basic Physics lectures in order to prepare themselves before attending lectures. As a result, students come to class with many problems and learning in the classroom becomes a place for discussion to solve problems. The logical consequence of this is that students' conceptual understanding will increase and deepen.

\section{References}

[1] McDermott, L. C., Shaffer, P. S.: Research as a guide for curriculum development: An example from introductory electricity. Part I: Investigation of student understanding. Am. J. Phys.60 (11), pp. 994-1003. (1992)

[2] Kim, E., Pak, S.: Students do not overcome conceptual difficulties after solving 1000 traditional problems. Am. J. Phys. 70 (7). pp. 759-765. (2002)

[3] Johnson, M.: Facilitating high quality student practice in introductory physics.Am. J. Phys. 69 (7).pp. S2-S1112. (2001)

[4] Coletta, V. P. dan Phillips, J. A.: Interpreting FCI scores: Normalized gain, preinstruction scores, and scientific reasoning ability. Am. J. Phys.73(12). pp. 1172-1182. (2005)

[5] McDermott. L. C., Redish, E. F.: Resource Letter: PER-1: Physics Education Research. Am. J. Phys. 67 (9). pp. 755-767. (1999)

[6] Hsu, L., Brewe, E., Foster, T.M., Harper, K.A.: Resource Letter RPS-1: Research in problem solving. Am. J. Phys. 72 (9). pp. 1147-115614. (2004)

[7] Heiner, C.E., Banet, A.I., Wieman, C.: Preparing students for class: How to get $80 \%$ students reading the textbook before class.Am. J. Phys.82(10). pp. 989-996. (2014)

[8] Sriyansyah, S. P., Suhandi, A., Saepuzaman, D.: Analisis konsistensi representasi dan konsistensi ilmiah mahasiswa pada konsep gaya menggunakan tes R-FCI. Jurnal Pendidikan IPA Indonesia.4. pp.75-82. (2015)

[9] Karim, S., Saepuzaman, D.: AnalisisKesulitanMahasiswaCalon Guru FisikaDalamMemahamiKonsepGerak Parabola. Prosiding Seminar Nasional Fisika (Universitas Negeri Jakarta, Jakarta, Indonesia). (2016)

[10] Karim, S., Saepuzaman, D. and Sriyansyah, S.P.: Diagnosis Kesulitan Belajar Mahasiswa Dalam Memahami Konsep Momentum. Jurnal Penelitian \& Pengembangan Pendidikan Fisika, 1(1), pp.85-90. (2015)

[11] Van Heuvelen, A.: Learning to think like a physicist: A review of research-based instructional strategies.Am. J. Phys.59(10). pp. 891-897. (1991)

[12] Van Heuvelen, A.: Overview, Case Study Physics. Am. J. Phys. 59(10). pp. 898-907. (1991)

[13] Meltzer, D. E.: The relationship between mathematics preparation and conceptual learning gains in physics: A possible "hidden variable" in diagnostic pretest scores. Am. J. Phys.70(12). pp. 12591268. (2002)

[14] Ambrose, B.S.: Investigating student understanding in intermediate mechanics: Identifying the need for a tutorial approach to instruction. Am. J. Phys.72(4). pp. 453-459. (2004)

[15] McDermott. L. C.: Oersted Medal Lecture 2001: "Physics Education Research - The key to student learning". Am. J. Phys. 69 (11). pp. 1127-113717. (2001)

[16] Lindsey, B.A. Liu, A.Y.: Combining two reform curricula: An example from a course with wellprepared students.Am. J. Phys.81(7). pp. 545-553. (2013) 
[17] Heller, P., Keith, R., Anderson, S.: Teaching Problem Solving Through Cooperative Grouping.Part 1. Group Versus Individual Problem Solving. Am. J. Phys. 60(7).pp. 627-636. (1992)

[18] Cummings, K., French, T. Cooney, P.J. (2002). Student textbook use in introductory physics.PERC Proceedings (Boise, ID, August 7-8, 2002), edited by S. Franklin, K. Cummings, and J. Marx (AAPT, 2002).

[19] Podolefsky, N., Finkelstein, N.: The perceived value of college physics textbooks: Students and instructors may not see eye to eye. Phys. Teach. 44(6). pp. 338-342. (2006)

[20] Subali, B., Rusdiana, D., Firman, H., Kaniawati, I.: Analisis kemampuan interpretasi grafik kinematik a pada mahasiswa calon guru Fisika. Prosiding SimposiumNasional Inovasi dan Pembelajaran Sains(InstitutTeknologi Bandung, Bandung, Indonesia). (2015)

[21] Karim, S., Saepuzaman, D. Sriyansyah, S.P.: Diagnosis kesulitan mahasiswa dalam memahami konsep momentum. Jurnal Penelitian dan Pengembangan Pendidikan Fisika1(1). pp. 85-90. (2015)

[22] Close, H. G., \& Heron, P. R.: Research as a guide for improving student learning: An example from momentum conservation. American Journal of Physics, 78(9), 961-969. (2010)

[23] Graham, T., \& Berry, J.: A hierarchical model of the development of student understanding of momentum. International Journal of Science Education, 18(1), 75-89. (1996)

[24] Stelzer, T., Gladding, G., Mestre, J. P., Brookes, D. T.: Comparing the efficacy of multimedia modules with traditional textbooks for learning introductory physics content.Am. J. Phys. 77(2). pp. 184-190. (2009)

[25] Finch, J.D., Hand, L.N.: Using an E-mail tutorial and student seminars to improve an intermediatelevel undergraduate physics course.Am. J. Phys.66(10). pp. 914 - 919. (1998)

[26] Zollman, D.: Oersted Lecture 2014: Physics education research and teaching modern Modern Physics. Am. J. Phys.84(8). pp. 573 - 580. (2016)

[27] Kohnle, A., Bozhinova, I., Browne, D., Everitt, M., Fomins, A., Kok, P., Kulaitis, G., Prokopas, M., Raine, D., Swinbank, E., et al.: A new introductory quantum mechanics curriculum Eur. J. Phys. 35. pp. 1-9. (2014)

[28] Gautreau, R. dan Novemsky, L.: Concepts first - A small group approach to physics learning. Am. J. Phys.65(5). pp. 418 - 428. (1997)

[29] Crouch, C.H., Mazur, E.: Peer Instruction: Ten years of experience and results. Am. J. Phys. 69, 970-977. (2001)

[30] McDermott, L.C.: Melba Newell Phillips Medal Lecture 2013: Discipline-Based Education Research-A View From Physics. Am. J. Phys.82(8). pp. 729-741. (2014)

[31] Kryjevskaia, M., Boudreaux, A., Heins, D.: Assessing the flexibility of research-based instructional strategies: Implementing tutorials in introductory physics in the lecture environment.Am. J. Phys.82(3). pp. 238 - 250. (2014)

[32] Cruz, E., O'shea, B., Schaffenberger, W., Wolf, S., Kortemeyer, G.: Tutorials in Introductory Physics: The Pain and the Gain. Phys. Teach.48. pp. 453-457. (2010)

[33] Steinberg, R.N., Wittmann, M.C., Redish, E.F.: Mathematical tutorials in introductory physics.The Changing Role of Physics Departments in Modern Universities: Proceedings of ICUPE, edited by E. F. Redish and J. S. Rigden. CP399. pp. 1075-1092. (1997)

[34] Sadaghiani, H.R.: Online multimedia prelab tutorials in conservation laws.PERC Proceedings CP1289 edited by C. Singh, M. Sabella, and S. Rebello (AAPT, 2010). (2010)

[35] Sriyansyah, S. P., Karim, S., Saepuzaman, D., Suhandi, A.: Investigation of students' scientific consistency and learning difficulties in the first law of thermodynamics.Proceeding on International Conference on Mathematics, Science and Education (Semarang State University, Central Java, Indonesia) (2015) 